\title{
NARRAR ES LUCHAR. MITOPOIESIS Y POLÍTICA EN LA OBRA DE WU MING
}

\author{
Narrating is Fighting. Mitopoiesis and Politics in Wu Ming's Work \\ Anxo Garrido Fernández \\ Universidad Complutense de Madrid \\ anxogarr@ucm.es
}

\section{Resumen:}

El presente artículo pretende señalar los vínculos existentes entre la apuesta política y narrativa de Wu Ming y la filosofía postoperaista italiana. A dicho fin, llevaremos a cabo una contextualización histórica del nacimiento del colectivo, un análisis de su concepto de mitopoiesis en relación a los estudios virnianos del trabajo posfordista y un estudio del vínculo entre las cartas de Toni Negri consagradas a la cuestión del arte y el modo en que Wu Ming auto-comprenden su trabajo y la figura del artista por excelencia: el narrador. Todo esto sin soslayar el trasfondo político de estas reflexiones.

\section{Palabras clave:}

Wu Ming, Negri, Virno, multitud, estética y política.

\begin{abstract}
:
The current essay aims to point out the connection between Wu Ming's political and narrative bet and the Italian postoperaist philosophy. To that end, we will do an historical contextualization to the birth of the collective, an analysis to his concept of mitopoiesis regarding virnians studies about postfordist labour and a study about the link between Toni Negri's letters devoted to the art matter and the way in which Wu Ming self-understand their work and the figure of the artist par excellence: the narrator. All this without ignoring the political background of these reflections.
\end{abstract}

Keywords:

Wu Ming, Negri, Virno, Multitude, Aesthetics and Politics.

Recibido: 22/10/2017

Aceptado: 26/12/2018 
En el fresco soy una de las figuras del fondo. En el centro destacan el Papa, el Emperador, los cardenales y los príncipes de Europa. En los márgenes, los agentes discretos e invisibles, que asoman desde detrás de las tiaras y las coronas, pero que en realidad sostienen toda la geometría del cuadro, lo llenan y, sin dejarse descubrir, permiten a aquellas cabezas ocupar el centro.

Q, Luther Blisset

La reciente publicación de El ejército de los sonámbulos, novela que narra el movimiento de las multitudes durante el periodo de La Convención y último éxito editorial del colectivo Wu Ming, viene a sumarse a una nutrida trayectoria en la que, junto a otras novelas (54 (2002), Manituana (2007), etc.), destacan el guión de Lavorare con lentezza (2004), película de Guido Chiesa ambientada en los años de la autonomía italiana, o el disco Bioscop (2014), del grupo Wu Ming Contingent, en el que participan, como vocalista y guitarrista respectivamente, dos de los miembros de la formación original. Hemos de remontarnos, sin embargo, hasta la época del Movimiento altermundista para rastrear los orígenes del grupo, pues es en las columnas italianas del Movimiento de Resistencia Global, cuyo apogeo político se concentra en el quinquenio final del pasado siglo y en los dos primeros años del $X X I$, y cuya infatigable innovación en los repertorios de actuación colectiva, en las prácticas de la protesta y en el afinado de los contornos simbólicos del antagonismo es todavía recordada, donde se gesta el estilo característico de Wu Ming.

Herederos de la filosofía obrerista italiana, el colectivo parece reconocer la polisemia incontrolable que aqueja al concepto de multitud y optará por una renuncia a las pretensiones sociológico-descriptivas del término para convertirlo en la piedra de toque de su concepción estético-política. La multitud pasa a ser la protagonista de un texto que aspira a dar cuenta de sus dinámicas y, así, conjura su emergencia, dotando de un imaginario común y unas narrativas compartidas a los movimientos que se oponen al Imperio. Es de este modo que Wu Ming ocupa su posición — si bien no exenta de originalidad - en la estela de la fecunda reflexión operaista, en tanto que esta, ya desde sus publicaciones seminales en Quaderni Rossi, dedicó una parte de su quehacer intelectual al estudio del vínculo entre producción estética y contradicciones sociales.

Nuestra hipótesis es clara: el (post)operaismo y la (post)autonomía son fenómenos —uno más teórico que práctico, más práctico que teórico el otro- que discurren parejos, se solapan y retroalimentan. Con este texto pretendemos iluminar, siquiera parcialmente, aquellos aspectos en los que, a propósito de la relación arte-política, ambas tradiciones convergen, $y$, a dicho fin, queremos acotar el espacio de nuestra 
modesta reflexión a partir de dos cuestiones planteadas por sendos fundadores de Potere Operaio: Antonio Negri y Sergio Bologna.

En la presentación que Negri redacta para la edición española de Arte y Multitudo - compendio de cartas escritas en diciembre de 1988 y publicadas finalmente en 1990-, describe del siguiente modo su experiencia bajo condiciones de subsunción real del trabajo en el capital:

Yo no encontraba el menor rastro de ese valor de uso. El mundo se había vuelto completamente reificado, abstracto: ¿Qué sentido podía tener el arte en una situación así? ¿Cuáles podían ser, en el seno de esa realidad, los procesos de producción artística, de creación alternativa, de reinvención de lo real? Esa percepción no era simplemente filosófica, era también política (Negri, 2016a: 11).

Negri se explica con claridad. En primer lugar, la pregunta filosófica por el arte implica necesariamente un cuestionamiento político: es también política. Con esto, como veremos, no se establece la preponderancia de una de las partes, sino una codependencia, una determinación bidireccional en la que el espacio de juego para el arte se encuentra políticamente determinado $y$, a un tiempo, el arte se concibe como la actividad capaz de desplazar los límites de la gramática en la cual se gesta. En otras palabras, la práctica artística juega con el espacio liminar de lo (im)posible, entre la liviandad de la reproducción y la testarudez de las resistencias, y funciona como un resorte en que se proyectan los puntos de fuga del modo de organización social vigente. Por lo tanto, el arte permite un éxodo intensivo, "reinventar lo real", nomadizarse en un mundo cuyos límites han sido exhaustivamente cartografiados al servicio de la dominación capitalista'

En segundo lugar, Negri apunta las barreras con las que se topa la producción artística en la actualidad. La subsunción real, el momento en el cual la totalidad de la organización social del trabajo responde a las exigencias de la extracción de plusvalor, implica una mediación absoluta del valor de cambio. Esta situación condena a la inaccesibilidad de la cosa — a la imposibilidad de disfrutar inmediatamente su valor de uso- en tanto que la naturaleza profunda de lo mercantil estriba en haber sido producido para el consumo de otro, es decir, para ser intercambiado. Es según esto que la totalidad de las experiencias posibles quedan circunscritas al interior del dispositivo de dominación capitalista, aun cuando Negri reserve al arte la fuerza

\footnotetext{
${ }^{1}$ Recordemos el célebre fragmento de Deleuze, autor que marca profundamente el pensamiento negriano: "el nómada no es necesariamente alguien que se mueve: hay viajes inmóviles, viajes en intensidad, y hasta históricamente los nómadas no se mueven como emigrantes sino que son, al revés, los que no se mueven, los que se nomadizan para quedarse en el mismo sitio y escapar a los códigos". (Deleuze, 2005: 330).
} 
imaginativa capaz de prefigurar un orden otro a partir de las potencias no realizadas en el presente, a saber, las del trabajo no capturado o solo parcialmente explotado. El arte será capaz, en otras palabras, de producir formas de vida, lucha y resistencia ajenas a la lógica de la mercantilización.

El texto de Bologna, por su parte, aun cuando se mantiene fiel a la heurística operaista que concede prioridad a las luchas en la producción sobre su captura por la dominación capitalista (incidiendo así en el carácter parasitario de esta última), es menos especulativo. Analizando las prácticas contestatarias surgidas en el periodo de hegemonía fordista y que serán reorganizadas y explotadas en el modelo laboral posfordista, Bologna llega a la siguiente reflexión sobre la relación entre estética y política:

Hace falta una profunda innovación en la estética de la protesta; hay que encontrar una nueva simbología, distinta de la de los sindicatos del trabajo por cuenta ajena [...]. Algunos componentes de esta área tan amplia del «trabajo precario» están experimentando nuevas simbologías de la protesta. En la medida en que los símbolos son vectores de comunicación, éstas proporcionan aglutinantes sociales en la actual crisis de las ideologías (Bologna, 2006: 143).

Para Bologna, una parte del antagonismo se juega en lo simbólico. Este espacio regido por leyes irreductibles — si bien no del todo independientes - a las demás esferas de lucha social, requiere de un análisis y una estrategia diferenciados si se pretende llevar a cabo una política crítica exitosa. En este sentido, al modo del mito soreliano, el arte no solo prefigura los espacios dentro del capital que resisten a su lógica, sino que también permite aglutinar fuerzas en torno a estos imaginarios alternativos, pensados a la contra de las formas de vida hegemónicas.

En este punto la propuesta de Wu Ming se encuentra con el operaismo. El colectivo circunscribe su tarea a las coordenadas impuestas por el neoliberalismo para, desde su interior, experimentar con nuevas formas estéticas y tipos de politicidad destituyente atentas a la dimensión simbólica. No es otro que este el sentido que los autores boloñeses dan el célebre dictum marxiano: "la fuerza material debe ser derribada por la fuerza material, pero la teoría se convierte en una fuerza material tan pronto como se adueña de las masas" ${ }^{2}$.

Dividiremos nuestra exposición en tres partes. En la primera de ellas nos ocuparemos de presentar a Wu Ming y los antecedentes teórico-políticos que le sirven de

\footnotetext{
${ }^{2}$ La cita, como es sabido, pertenece a la "Introducción para la crítica de la Filosofía del derecho de Hegel" (1844), de Karl Marx. La reproducimos, frente a otras traducciones posibles, tal y como aparece en: Wu Ming, 2002: 186.
} 
inspiración. El segundo apartado consistirá en un análisis de los conceptos centrales de la reflexión wumingiana: el mito y la mitopoiesis. Finalmente nos ocuparemos con la cuestión del arte, el artista y la narración, atendiendo al encuentro con la filosofía operaista y a la modulación específica de tales nociones en el capitalismo contemporáneo.

\section{CUANDO EL NOMBRE NO IMPORTA}

Wu Ming - "sin nombre" en chino mandarín— es la fórmula con que los escritores disidentes del gigante asiático firman sus obras. Es también el pseudónimo bajo el cual han escrito Roberto Bui, Giovani Cattabriga, Luca di Meo y Federico Guglielmi a partir del año 1999. Este sujeto colectivo, formado por miembros boloñeses del Tutte Bianche y del Luther Blisset Project, comienza su producción literaria con $Q$ (1999), novela firmada con el alias colectivo y de uso libre Luther Blisset y que alcanzó un notable éxito de crítica y ventas pese a haber sido publicada bajo una forma de propiedad intelectual que anticipaba los términos del copyleft ${ }^{3}$.

Precisamente esta reivindicación de los bienes comunes del conocimiento, junto a las prácticas del Movimiento Antiglobalización y las innovaciones en las luchas políticas introducidas por el Ejército Zapatista de Liberación Nacional (EZLN); serán los tres antecedentes fundamentales de Wu Ming.

\section{a) Luther Blisset Project.}

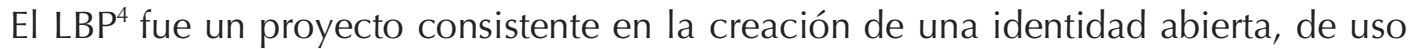
libre y no jerárquica, descrita por alguno de sus miembros como un plan quinquenal de producción artística activo entre dos hitos señeros del Movimiento Antiglobalización: el levantamiento zapatista de 1994 y La Batalla de Seattle del año 1999.

La aparición del proyecto coincide con las esperanzas puestas en internet como una herramienta de organización política que hacía posible, por ejemplo, que grupos de activistas —en muchas ocasiones desconocidos entre sí- pudiesen coordinar actuaciones de muy diversa índole incluso a nivel internacional. Y no solo esto,

\footnotetext{
${ }^{3}$ Para una detallada introducción a la cuestión del copyleft y a los límites del modelo antagonista inspirado en las luchas contra el copyright, véase: Rendueles, 2003: 41-93.

${ }^{4}$ Luther Blisset es el nombre de un futbolista jamaicano, internacional con Inglaterra y primer delantero negro en anotar un hat-trick con la selección británica. Posteriormente jugó con el AC Milan, pero, al no adaptarse al estilo de juego italiano, pronto fue conocido por su escasa vitalidad y se convirtió en blanco de los insultos de los tifosi. No es de extrañar que un personaje con dichas características - un outsider - representase una generación de activistas marcada a partes iguales por el western y las teorías del antipoder.
} 
sino que, debido al anonimato, permitía la puesta entre paréntesis de las reivindicaciones identitarias y las formas de actuación específicas de cada grupo, posibilitando una interesante hibridación entre herramientas procedentes de múltiples tradiciones políticas.

Como resultado se llevaron a cabo acciones de "guerrilla de la comunicación", se crearon radios autogestionadas en las que se emitían programas interactivos, se produjeron novelas, ensayos, acciones de "sabotaje cultural" y hasta un fraude a la editorial Mondadori (perteneciente en parte a Silvio Berlusconi) por la que ésta llegó a publicar, como si de un caso de vanguardia literaria se tratase, una obra firmada por Luther Blisset y compuesta por textos descargados aleatoriamente de internet. Esta última actuación supuso un fuerte agravio en la credibilidad de la editorial que reforzó notablemente las posiciones de sus trabajadores, en huelga por aquel entonces (1996).

Aunque se desconoce quién fue el creador del pseudónimo, suele considerarse al movimiento estudiantil "La Pantera" como pionero en la experimentación de este tipo de prácticas. Surgido al calor de la ocupación de la Facultad de Letras de Bolonia en el año 1990 (Wu Ming, 2002: 61), da pie a la creación de una "oficina de agitación y propaganda" de la que surgirán diferentes grupos que terminan por utilizar el alias. Estos, al modo de las prácticas partisanas, pretendían elaborar estrategias de comunicación y confrontación no-frontal con diferentes sectores de la industria cultural italiana, intentando dirigir la distorsión que de por sí se le presuponía a los medios de comunicación mediante trabajos de infiltración y preconstitución del terreno informativo. Como ejemplo de esto, en un texto titulado "Un día de sol en Kreuzberg y una grabadora", Wu Ming atribuyen a esta guerrilla cultural el hecho de que el término multitud, restringido hasta entonces a los círculos conocedores de la filosofía de Spinoza, Ilegase a ser de uso común los meses de 2001 anteriores a la cumbre genovesa del G8 (Wu Ming, 2002: 64).

b) La carta de Milan, el Tutte Bianche y el resurgir de la autonomía.

La carta de Milán supone un cambio programático en la política contracultural italiana. Concebida como un modo de aglutinar a los centros sociales del norte bajo una estrategia común, marca el punto de inflexión para un abandono de la estrategia de la tensión — propia de los Anni di piombo - que deja espacio a nuevas formas de desobediencia civil. Estas se apoyan sobre narrativas del conflicto novedosas que permiten deconstruir prácticamente distinciones binarias — como violencia/no-

${ }^{5}$ No resulta trivial, entonces, que Wu Ming se haya negado explícitamente a tomar los "Años de plomo" y el imaginario de las Brigate Rosse como fuente para su trabajo mitopoietico. 
violencia - útiles al relato del poder, en tanto que servían de apoyo a la estrategia estatal de criminalización de los movimientos sociales. Con este giro se abandona el imaginario del duelo y la lucha sin cuartel para - con un gramscismo velado inasumible para un universo simbólico, el del postobrerismo ${ }^{6}$ y los movimientos sociales italianos, en que el legado del sardo se vincula estrechamente con el estalinismo togliattiano y los límites de la política nacional- reconocer toda una sociedad civil con la que entablar relaciones y en la que buscar apoyos. Para ello ha de comenzarse un diálogo con las instituciones locales que, en casos como el de Nápoles, han terminado por reconocer a los centros sociales como bienes comunes autónomos y al margen de la gestión municipal.

Es en este contexto que aparecen los Tutte Bianche con una estrategia, práctica y simbólica a la vez, que combina el uso de la desobediencia civil protegida con nuevas formas de comunicación basadas en la gestión mediática del conflicto. Su primera aparición se remonta al año 1998, cuando, ante las reiteradas negativas de las autoridades locales, se fuerza, mediante prácticas de confrontación no agresiva, la entrada de un grupo de periodistas al centro de reclusión de inmigrantes de Trieste, a fin de que estos pudiesen dar cuenta de la situación del centro. A partir de entonces el uso del mono blanco y las protecciones, así como la estrategia cuasi teatral del choque no-violento (que en ocasiones consensuaba previamente los niveles de represión policial), se popularizó en todas las apariciones del movimiento antiglobalización.

Todos los miembros de Wu Ming tomaron parte en las prácticas de los Tutte Bianche y escribieron una ingente cantidad de relatos destinados a producir el imaginario adecuado al nuevo tipo de lucha: el del asedio y la infiltración, el de las multitudes contra el imperio. Véase un ejemplo del cuidado que estos autores prestaban a los matices simbólicos de la protesta:

Poco a poco [el mono blanco] comenzó a ser utilizado como metáfora del nuevo trabajo "flexible", "precario", "intermitente", "post-fordista", "postindustrial", "atípico". Los monos blancos no eran los monos azules, los de los obreros tradicionales. Como el blanco es la suma de todos los colores se tomó como alegoría de la diversidad; no hay solo un mono azul, sino que los hay de todos los colores y en lugar de estar uno junto a otro y punto, como en el arco iris, se funden y se convierten en el blanco que se obtiene al hacer rodar el disco cromático (Wu Ming, 2002: 62-63).

\footnotetext{
${ }^{6}$ Recordemos que es Giovanni Arrighi, autor fuertemente influido por Gramsci, quien acuña el término operaismo. Sin embargo, la obra seminal de dicha corriente, Obreros y Capital, de 1966, se la debemos a Mario Tronti.
} 
C) El zapatismo.

El levantamiento zapatista coincide con la entrada en vigor del NAFTA — tratado de libre comercio entre Estados Unidos, México y Canadá por el cual, entre otras cosas, se anulaba la propiedad indígena sobre la tierra- el 1 de enero de 1994. Dicho levantamiento, que pronto rechaza las estructuras vanguardistas e intenta amoldarse al imaginario indigenista, aspiraba no solo al derrocamiento del entonces presidente Carlos Salinas de Gortari y la implantación en México de una democracia participativa, sino también a hacer visibles algunos de los efectos perniciosos de la globalización neoliberal. Aunque sus resultados fueron más humildes, sí consiguió avanzar en la creación de prácticas democratizadoras, comunidades autogestionadas y en el tejido de una red de activismo transnacional que atendiese simultáneamente a las dimensiones global y local.

La horizontalidad en su organización, el rechazo a la toma del poder y la cuidada forma en que este movimiento gestionó el uso de los mitos y la simbología de cara a ganarse la simpatía de la sociedad mexicana, hacían del EZLN un movimiento original, cuyas prácticas resultaban inconmensurables con las guerrillas tercermundistas.

Desde el bricolaje mítico (claro precedente de la mitopoiesis wumingiana) que reformulaba pasajes de la tradición maya o de la historia mexicana, hasta el propio personaje conceptual de Marcos: un subcomandante — pues el comandante es el pueblo según algunas interpretaciones, o Zapata según otras- perpetuamente oculto tras un pasamontañas que había de servir como espejo para todas las clases subalternas; el neozapatismo construyó herramientas novedosas, tanto en la forma como en las reivindicaciones, inspiradoras para los movimientos sociales de todo el mundo que convergerían por primera vez en 1999, durante la Batalla de Seattle.

\section{MITO Y MITOPOIESIS}

"El arte es un poder constituyente" (Negri, 2016a: 63).

Esta cuestión del poder constituyente, con la que nos ocuparemos ahora, no es ajena a las mutaciones semánticas que sufre la totalidad del léxico político con el tránsito a la posmodernidad (Negri, 2008: 17). Frente a la concepción moderna que concibe al poder constituyente como un acto fundante que se agota en el poder constituido, Negri señala un desajuste estructural entre la potencia constituyente irrestricta que requiere de una teoría del poder absoluto y expansivo, y el constitucionalismo (de la índole que fuere) como teoría del poder limitado. En base a esta distinción, ya desde las primeras páginas del libro que consagra al estudio de este concepto, Negri sostiene la existencia de una asimetría esencial e insuperable que 
se hace patente en el carácter necesariamente excesivo de la potencia democrática con respecto a los dispositivos diseñados para domesticarla.

Dicho esto, solo si nos hacemos cargo de una serie de nociones negrianas que completan la constelación conceptual en la que se enmarcan estos conceptos, podremos acotar el sentido específico en que el arte es para el autor una potencia constituyente. Veamos para ello el siguiente fragmento de El trabajo de Dionisos:

No se puede engullir entera y asimilar tan fácilmente la realidad de la revolución [...]. El trabajo vivo plantea un dilema trágico para el constitucionalismo. Por una parte, el trabajo vivo es el poder constituyente de la sociedad. Se presenta como lugar creativo y vital, una fábrica dinámica de valores y normas. Sin embargo, al mismo tiempo, el trabajo vivo presenta una crítica de todo poder constituido, de todo orden constitucional fijo. (Negri y Hardt, 2003: 36)

Hay un trabajo vivo y concreto - diferente del trabajo humano indiferenciadoque produce valor y alimenta los dispositivos de captura biopolítica del capital. Esta trabajo vivo, que Negri asimila también al poder constituyente, es excesivo, supera los marcos del poder constituido, los niega y pugna por suprimirlos construyendo formas de vida y espacios de libertad disfuncionales a la lógica de la valorización. Nos encontramos aquí con los dos tópicos operaistas: en primer lugar, la prioridad de un trabajo vivo que es parasitado en la producción y, en segundo lugar, la particularidad de la mercancía "fuerza de trabajo" como aquella que, al imponer condiciones a (y diferir en el tiempo) la realización de su valor de uso, introduce, desde su interior, fricciones en el funcionamiento del proceso capitalista.

Aun cuando la totalidad de la vida ha sido capturada, el trabajo conserva una autonomía relativa que impone ciertas condiciones (debidas, por ejemplo, a los límites insuperables de la corporalidad) a su inserción en el engranaje de unos procesos de valorización que, a la vez, requieren de este trabajo vivo para su propio funcionamiento. Precisamente por esto, tal trabajo vivo conserva siempre una cierta ambivalencia — que Paolo Virno elaborará con su concepto de multitud (2011)— consistente en su capacidad de movilizar las mismas herramientas que sirven al proceso de valorización en empresas que resisten a este ${ }^{7}$.

\footnotetext{
${ }^{7}$ La misma idea está en el estudio de la mentalidad italiana post-68 que realiza Sergio Bologna: "la fuerte propensión a la autoorganización, a la puesta en marcha de actividades culturales autogestionadas, había formado un débil territorio del que podía partir una trayectoria más larga de construcción de 'alternativas` de vida, siguiendo la fórmula más tradicional del trabajo autónomo [...] La palabra 'alternativo` que se anteponía a muchas de estas
} 
El planteamiento de Wu Ming en torno al mito y la mitopoiesis seguirá los meandros de la problemática negriana. Las mitologías propias de los movimientos sociales actuales pueden rastrearse en las leyendas urbanas y los héroes colectivos que como Marcos para los zapatistas o el propio Luther Blisset para el MRG-contribuyen al imaginario compartido que vertebra a los sujetos antagonistas. Cabe destacar, más allá de los ejemplos que aducen en sus textos, dos referencias filosóficas que sirven a los autores para desarrollar su teoría del mito: Émile Durkheim y Georges Sorel (Fernández-Savater y Wu Ming, 2003: 52). De la convergencia de los planteamientos de ambos, surge una concepción original del mito en la que este, como una suerte de conatus comunitario, funciona a la vez como lecho simbólico compartido y como mecanismo de empoderamiento que permite acometer las tareas de transformación social. Tal y como pensaba Durkheim, el mito ha de entenderse como una argamasa social, punto de referencia que codifica y cohesiona los ritos cotidianos de la comunidad ${ }^{8}$. De Sorel, en cambio, se toma una concepción del mito no solo reproductiva, sino energética y dinámica: se ve este como un polo de agregación y concentración de las energías revolucionarias que dirige la lucha que aspira a la transformación del estado de cosas existente.

El mito es entonces, simultáneamente, constituyente y destituyente. Relata un acto inaugural que, en las versiones reaccionarias como la de Eliade, se sitúa in illo tempore (Wu Ming, 2002: 42) y que, mediante el rito, se perpetúa en aras de la reproducción social. No obstante, frente a tendencias a la fetichización de este tipo, el mito wumingiano se abre a la multiplicidad, a un campo de lo mítico en donde la pugna entre diversas narrativas fuerza la evolución o eliminación de los sistemas rituales obsoletos. El mito, en una relación de isomorfa con el arte, ha de entenderse como "trabajo vivo, siempre subyugado pero siempre liberándose" (Hardt y Negri, 2003: 12) que se reproduce diferencialmente a fin de evitar la deriva identitaria y auto-referencial que lo privase de su potencia transformadora. Mito y mitopoiesis son, en tanto que la supervivencia de la comunidad siempre requiere variaciones en su identidad, indiscernibles. La sujeción a la inmanencia, que ha de garantizarse con el rechazo de la multitud a las palabras-propaganda, el Líder o el origen trascendentes, asegura este carácter abierto del mito que permite a la comunidad el diferir de sí.

iniciativas era con frecuencia una máscara para ocultar la 'falsa conciencia` de quien pasada de las utopías revolucionarias a una existencia pequeñoburguesa" (2006: 36).

${ }^{8}$ Esta idea fue desarrollada en el mito de los tamarianos, escrito por alguno de los miembros del LBP: "los tamarianos citan acontecimientos sacados de su historia y de su mitología, acontecimientos que representan precedentes/recuerdos a partir de los cuales pueden hablar en cualquier circunstancia actual" (Luther Blisset, 2000: 2). 
Entendemos entonces por qué el narrador (para Wu Ming, figura del artista por excelencia) y el trabajo mitopoiético que este realiza, funcionan como "un cómodo vehículo a través del cual la "biblioteca" de una comunidad trata de replicarse a sí misma" (Wu Ming, 2002: 47). El trabajo vivo del narrador es el resorte con el que mito y presente se retroalimentan, garantizando que el primero conserve sus funciones emancipatorias ${ }^{9}$. La mitopoiesis, en tanto que trabajo de fragmentación de los mitos fetichizados que subyugan estas potencias, posee varias implicaciones: en primer lugar, la renuncia a la posibilidad de la crítica exhaustiva del mito, a un desencantamiento total de la realidad política que la reduciría a mera gestión; en segundo lugar, el planteamiento de la dimensión simbólica como un espacio de lucha en cuyo interior narrativas diferenciadas pugnan por representar legítimamente la realidad. En este específico punto, el planteamiento de Wu Ming es formalmente idéntico a la estrategia diseñada por Barthes en Mitologías:

Parece por lo tanto extremadamente difícil reducir al mito desde el interior, pues ese mismo movimiento que hacemos para liberarnos de él, de pronto se vuelve una presa del mito: el mito puede, en última instancia, significar la resistencia que se le opone. Realmente la mejor arma contra el mito es, quizá, mitificarlo a su vez, producir un mito artificial (Barthes, 2000: 229).

¿Qué caracteriza hoy a este proceso infinito de mitopoiesis? Wu Ming asumen explícitamente los análisis de Paolo Virno respecto al posfordismo (FernándezSavater y Wu Ming, 2003: 55) y a las consecuencias de esta mutación en el régimen laboral, siendo una de las líneas de fuerza y punto común a ambos análisis el postular la pérdida de una comunidad sustancial, de una trama simbólica compartida que suministre, mediante la seguridad ritual, una salvaguarda frente a la incertidumbre. Las consecuencias de esta generalización del riesgo como gramática propia de la experiencia posfordista han de ser consideradas.

Aunque las referencias filosóficas a partir de las que Virno analiza este particular son amplias, este no hace sino aislar un patrón isomorfo en el pensamiento de diferentes autores. Así, partiendo de la analítica kantiana de lo sublime, el italiano distingue entre un plano de peligrosidad empírica y uno de inseguridad trascendental (Virno, 2016: 29-30), donde el segundo de los niveles no puede hallar reparo en esta o aquella salvaguarda concreta, sino que requiere de una protección respecto a un otro indeterminado, frente a una peligrosidad trascendental que el autor operaista atribuye a la carencia de instintos especializados característica del umwelt humano.

\footnotetext{
${ }^{9}$ No es otro el sentido en el que Negri habla del artista como "conducto entre la acción colectiva que construye ser nuevo, nuevo significado, y el acontecimiento de liberación que fija esta nueva palabra en la lógica de construcción de ser" (Negri, 2016a: 70).
} 
La distinción kantiana —apunta Virno- se replica en el §40 de Sein und Zeit, donde Heidegger distingue el miedo de la angustia. Esta última, cuyo sentimiento correspondiente es la desazón, funciona como trascendental de todo miedo concreto, descrito como el "'modo' existencial del no-estar-en-casa" (Heidegger, 2009: 207). Virno, habida cuenta de esto, interpreta la ausencia posfordista de una comunidad sustancial y la atomización social creciente como una condena al ostracismo perpetuo del no-estar-en-casa, debida a la pérdida de legados simbólicos, del ethos de unas prácticas compartidas que servían para paliar la angustia particular con la urdimbre simbólica compartida por la comunidad.

Dicha comunidad éthica se encuentra, en opinión del napolitano, a la base de las categorías políticas modernas como la de pueblo o soberanía, toda vez que estas respondían a la posibilidad de establecer distinciones rígidas entre un ámbito de pertenencia y un más allá de la comunidad, o sea, permitían delimitar un afuera. El concepto de multitud hoy en boga, presupone ya una cierta porosidad en las fronteras sociales e implica que los límites que otrora garantizaban la seguridad del individuo se desdibujen. Ejemplo de estas fronteras nítidas sería el contrato hobbesiano, donde el acto constituyente consistía en un intercambio de seguridad por obediencia resultado del cual el pueblo tomaba entidad. Frente a este, la multitud representaba — también para Hobbes - la acontractualidad, la persistencia de lo múltiple en la esfera pública que no capitula ante los intentos de expropiación y monopolización de la agencia política (Virno, 2016: 21-22). No es de extrañar entonces que la multitud se considere el modo de ser predominante en la posmodernidad, época inaugurada por la —-supuestamente y siempre según estos autores_ "crisis del Estado-nación" (Negri, 2008: 9).

Toda esta retórica virniana no es más que un rodeo asaz especulativo para referirse a la situación de incertidumbre derivada de la extensión de la forma-empresa (y la consolidación de la ficción jurídica de la empresa unipersonal para referirse al trabajo autónomo) como unidad mínima del análisis social; de la generalización de la precariedad existencial debida al fin del control sindical oligopólico sobre la oferta de fuerza de trabajo - con el consiguiente abandono del objetivo políticoeconómico del pleno empleo y la elevación del desempleo estructural-que caracterizan a la institucionalidad neoliberal; y, concomitante a estas, de la extensión (y precarización) de la terciarización que, en los albores del posfordismo, se consideró como un sector dinámico ${ }^{10}$ susceptible de reactivar los procesos de valorización en

\footnotetext{
${ }^{10}$ Análisis, creemos, compartido por la fe operaista en la capacidad emancipatoria del (mal)llamado trabajo inmaterial.
} 
tanto que diseminaba y empleaba el capital variable excedente que hacía caer la tasa de ganancia.

Sea como fuere, Virno y Wu Ming coinciden en el diagnóstico y en la necesidad política de elaborar relatos compartidos que, siempre de una forma precaria y contingente que los somete a reelaboración continua, permitan orientarse en el mudable terreno del presente. Es la propia posmodernidad la que obliga a la incesante labor de mitopoiesis, y será la poiesis específicamente posfordista la que Wu Ming asuma como punto de partida para la creación de mitos. En Gramática de la multitud, Paolo Virno intenta dar una imagen de este trabajo posfordista a partir de las mutaciones acaecidas sobre la tríada aristotélica que estructuraba la experiencia humana: poiesis, praxis y episteme.

Si bien el modo de producción —entendiendo por tal no solo una configuración económica, sino, al modo de los regulacionistas, también "el conjunto de formas de vida, una constelación social, antropológica y ética [...] relativa a las costumbres, usos y hábitos, no al deber ser" (Virno, 2016: 47)— fordista todavía permitía una distinción relativamente nítida entre las diferentes esferas, con intersecciones o acciones recíprocas meramente externas entre ellas, el posfordismo se caracteriza por la mutua contaminación de trabajo, acción política e intelecto.

Así, cuando todavía eran discernibles:

El trabajo es el intercambio orgánico con la naturaleza, la producción de objetos nuevos, en fin, un proceso repetitivo y previsible. El intelecto puro tiene una índole solitaria y poco llamativa: la meditación del pensador escapa a la mirada de los otros, la reflexión teórica acalla el mundo de las apariencias. Al contrario del trabajo, que manipula materiales naturales, la acción política interviene en las relaciones sociales, tiene que ver con lo posible y también con lo imprevisto, no atesta el contexto en el que opera con un mar de objetos ulteriores sino que modifica ese mismo contexto (Virno, 2016: 48).

Mientras la poiesis se objetiva en un producto externo y material perfectamente diferenciado de la acción del productor, la praxis queda circunscrita al ámbito de un saber hacer con la contingencia y a una capacidad de transformación cualitativa de la realidad efectivamente existente. O dicho de otro modo: mientras que la poiesis posee un tèlos extrínseco a la acción, la praxis es "autotélica". La figura del virtuoso, es decir, aquel cuyo trabajo — al igual que la acción política — se caracteriza por la exposición pública y por una interpretación que pese a agotarse en sí misma se funda en una partitura (en una obra precedente) es, según Virno, la categoría límite que permite la distinción entre ambas formas de experiencia. 
Pues bien, dicho esto, la tesis fundamental de Gramática de la multitud es que el trabajo posfordista se caracteriza por una progresiva subsunción de la esfera del trabajo en la de la praxis. Siguiendo el itinerario inverso al descrito por Arendt en La condición humana, ya no es el mundo del trabajo el que coloniza la esfera política, sino que la esfera laboral se revela política de principio a fin, ya que las características propias del trabajador resultan ser ahora las del virtuoso. Pero, ¿cuál es la partitura que interpreta este virtuoso? Virno apela aquí al famoso concepto marxiano de General Intellect. Como es sabido, en el conocido pasaje sobre las máquinas de los Grundrisse, se sostiene que el grado de progreso de la investigación tecnocientífica condiciona la composición orgánica del capital. En otras palabras: el perfeccionamiento de las máquinas incrementa la rentabilidad de la producción reduciendo el recurso necesario a fuerza de trabajo. Este General Intellect con un fuerte resabio idealista que Marx circunscribe al capital fijo es expandido por Virno a la esfera del trabajo en general: "mientras la producción material de objetos es demandada al sistema de máquinas especializadas, las prestaciones del trabajo vivo, en cambio, se asemejan cada vez más a prestaciones lingüístico-virtuosas" (Virno, 2016: 58). El virtuoso posfordista, quien prácticamente monopoliza la actividad laboral una vez que el perfeccionamiento tecnocientífico reduciría al mínimo la necesidad de trabajo en el sentido fordista, es aquel capaz de valorizar fenómenos estrictamente circunscritos al ámbito del pensamiento, hacer de los pensamientos una "abstracción real", tangible, una mercancía con valor.

Este trabajo posfordista es público, colaborativo (creciente importancia del trabajo en grupo), basado en el lenguaje (importancia del marketing y la publicidad), consiste en entablar relaciones $y$, en gran medida, en la reorganización (pensemos en la logística como sector central del posfordismo ${ }^{11}$ ) de la relaciones existentes, más que en la creación de mercancías extrínsecas al propio proceso de trabajo. Estamos, en fin, ante un trabajo en el que la poiesis es eminentemente práxica y se realiza sobre la base de un trabajo intelectual (episteme) ya no privado, sino público.

La mitopoiesis es un ejemplo claro de cómo se produce en común algo fundamentalmente inmaterial, que aspira a ser público y a intervenir sobre una realidad contingente de un modo intensivo más que sustantivo. Resta mostrar con qué tipo de caracterización del arte y el artista concuerdan estas características.

\footnotetext{
11 "La logística no es el aglutinante que mantiene unido un universo multiforme, es el orden de este universo" (Bologna, 2006: 122).
} 


\section{ARTE, ARTISTA Y NARRACIÓN}

Una premisa subyace y emerge recurrentemente en la reflexión estética de Antonio Negri: la actividad artística se circunscribe siempre a un determinado modo de producción y, en tanto que modalidad específica de la fuerza de trabajo, se encuentra determinada por la división laboral predominante en este. Es por eso que la reflexión negriana acerca de las expresiones artísticas de vanguardia, se transforma considerablemente desde las cartas escritas a finales de los años ochenta —en pleno reflujo de las prácticas antagonistas en Italia y con Negri en el exilio- y las reflexiones de los años noventa, cuando el post-autonomismo parece haber encontrado formas de expresión y actuación que posibilitan prácticas antagonistas efectivas.

Asumiendo que la subsunción real imposibilita una producción artística mimética, pues no hay un afuera no-capitalista al cual pudiera tomarse como modelo, ésta queda circunscrita a una paradoja teórica: siendo interna al capitalismo, solo $-\mathrm{y}$ esta tesis de Negri es central- es verdaderamente artística en tanto que impugna dicho modo de producción, en tanto que produce las coordenadas de un acontecimiento que interrumpa la lógica mercantil. Para entendernos: es un pre-requisito de lo artístico el que este pueda solventar en la práctica la paradoja que referíamos. Por lo tanto, el arte considerado desde el prisma del trabajo vivo, será una específica modulación de este que, desde el interior del sistema, lleve a cabo un doble movimiento de deconstrucción-constitución.

Por esto precisamente, toda práctica artística es hoy poiesis - y ya no mímesisque asume la abstracción generalizada que implica el repliegue del valor de uso a un segundo plano - la conversión de las cosas en mero reflejo de su valor para el mercado-y, desde ahí, actúa en el quicio del "sublime mercantil", en el espacio liminar que permite hacer de la imaginación una "razón concreta y sutil que atraviesa el vacío y el miedo, la infinita serie matemática del funcionamiento del mercado, para determinar un acontecimiento de ruptura" (Negri, 2016a: 38).

Este acontecimiento de ruptura atraviesa el desierto de lo abstracto (Negri, 2016a: $69)^{12}$. O en otras palabras, se ha de entender por arte en el esquema de Negri a aquella vanguardia que, desde la pura inmanencia, prefigura alternativas emancipatorias y hace posible proyectar una recombinación radical de los elementos singulares ya dados que los libere del dominio del capital: "[en el arte] el poder colectivo

${ }^{12}$ Cabe destacar la importancia que Wu Ming conceden a esta imagen: "Ios mitos (en plural) son narraciones dinámicas y espurias, relatos que nos permiten superar la cuadragésima noche en lo ignoto (el desierto, las fases de incertidumbre en el conflicto social)" (Wu Ming, 2002: 42). 
de la liberación humana prefigura su destino" (Negri, 2016a: 63). Pero, y conviene advertirlo, erraríamos si confundiésemos este vanguardismo con un supuesto privilegio ontológico o epistemológico del artista individual. El arte, por contra, ha de entenderse como un presupuesto necesario del acto revolucionario - acontecimiento de entre los acontecimientos-, cuyo artista, cree Negri, es siempre la multitud. La cuestión de fondo, entonces, no es tanto la de qué producción artística puede activar los resortes revolucionarios, sino más bien la del modo en que se produce un relato revolucionario-una gramática novedosa- y el sujeto colectivo correspondiente que haga pensable tal acontecimiento: "la atracción del acontecimiento hacia el relato y el concluirse del relato en el nuevo acontecimiento" (Negri, 2016a: 70).

No es otra la idea de Félix Guattari, traída a colación por Raúl Sánchez en una carta a Negri en diciembre de 1999, en la que se piensan las historias como la propedéutica del acontecimiento. La historia, sucesión infinita de acontecimientos, será pues la linealidad surgida de una voluntad político-artística que se sustrae al desenvolvimiento inercial y circular de la reproducción capitalista:

La función constitutiva de las prácticas artísticas implica que su función central no consiste en contar historias, sino en crear dispositivos en los que la historia pueda hacerse (Guattari en Negri, 2016: 19).

La posibilidad de hablar de un trabajo liberado que produce belleza (arte en el sentido ya referido) estriba en reconocer la distinción negriana entre labor y work ${ }^{13}$. Las potencias sociales que se liberan del mando capitalista, en tanto que puestas al servicio del común y no de la extracción de plusvalía, son capaces de producir un éxodo sobre el que desarrollar nuevas formas de vida.

Si bien en condiciones fordistas - como hemos descrito- este éxodo tenía que atravesar la abstracción a la que se había sometido al trabajo; con la preponderancia adquirida por el trabajo intelectual en condiciones posfordistas, la vida ya no se ve subsumida en la abstracción, sino que, muy al contrario, la ha asumido: el trabajador intelectual utiliza el lenguaje como una prótesis, como códigos comunes que moviliza en su trabajo productivo. Y así,

si ya no hay arte se debe a que los cuerpos se han apropiado de él; está verdaderamente por todos lados en las prácticas de la multitud; dentro de los cuerpos el arte experimenta nuevas composiciones metamórficas: ¡Cuánto puede el cuerpo! Así, el arte ha dejado de ser una consolación, y

\footnotetext{
${ }^{13}$ Entendemos por labor "el trabajo vivo [que] produce y constituye la sociedad en un tiempo que no respeta la división que establece la jornada laboral, dentro y fuera de las prisiones del trabajo capitalista (work) y de su relación salarial, tanto del ámbito del trabajo, como del no-trabajo" (Negri y Hardt, 2003: 7).
} 
asimismo de representar cualquier tipo de polaridad trascendente o trascendental... Es vida, es incorporación, es trabajo... El arte ha dejado de ser una conclusión; el contrario, es un presupuesto. Sin alegría, sin poética, ya no habrá revolución. Una vez más el arte se ha anticipado a la revolución (Negri, 2016a: 80).

Wu Ming asume esta intelectualización del trabajo posfordista ${ }^{14} y$, al modo descrito, piensan el contar historias — al narrador que replica las funciones del bardocomo un modo de producción de un horizonte receptivo al acontecimiento. El marco en el cual se desarrolla esta reflexión, circunscrito a la división social del trabajo, huye de hueros tipos ideales en los que el artista es un genio en contacto "con dimensiones más elevadas del ser" (Wu Ming, 2002: 34) y asume el diagnóstico negriano por el cual si el artista es un ser superior lo es solo en tanto que ser colectivo y que sirve al común. No es otra, teniendo esto en cuenta, la manera en que ha de comprenderse la concepción del artista-activista como artesano de la narración, en un plano horizontal con respecto a los demás trabajadores de una comunidad:

Que el estereotipo del artista 'mortificado' y 'atormentado` despierte mayor interés en los medios y tenga mayor peso de opinión que el esfuerzo de quien limpia las fosas sépticas nos hace comprender en qué sentido la actual escala de valores está distorsionada (Wu Ming, 2002: $34)$.

Su caracterización parte, efectivamente, de la presuposición del artista colectivo - tomando por modelo el teatro isabelino o la novela por entregas que permitía un feedback entre el lector y el escritor- y completa la mundanización de la labor artística con una renuncia a la imagen demiúrgica del creador que toma pie en el elogio del plagio como punto cero del que participan todas las técnicas de producción artística. La desacralización de la obra y la "socialización" de los resultados artísticos, se fundan sobre una consideración del arte (muy marcada por el papel preponderante que se concede a la narrativa) como un bien no-rival, es decir, no sujeto al principio de escasez que hace que el consumo por parte de un particular restrinja el acceso al mismo bien por parte de otro. Desde este prisma se entiende que Wu Ming considere el arte como intrínsecamente excedente y no asimilable a los meros soportes materiales capturables por el mercado. Es con este gesto evasivo, radicalmente antielitista, que los autores confrontan toda estética que goce del poder de disertar sobre la verdad de lo bello y aspiran a elaborar una poética ${ }^{15}$ : un

\footnotetext{
14 “Qué estatus puede ya reclamar para sí un escritor cuando narrar historias es solo una de tantas tareas del trabajo mental [junto a] la programación se software, el diseño, la música, el periodismo, la información, los servicios sociales, etc.?" (Wu Ming, 2002: 30).

${ }^{15}$ Para esta distinción, véase: Negri, 2016a: 79.
} 
discurso productivo con repercusión política. Es a la luz de todos estos factores que estamos en condiciones de comprender sin aspavientos la defensa a ultranza que miembros del LBP realizaron de Piero Cannata, artista conocido y encerrado por romper a martillazos el pie izquierdo del David de Miguel Ángel.

Pero si hay una idea que concentre la crítica de Wu Ming, esta sería la de la propiedad del arte. Para el grupo, el arte es un sedimento filogenético, la autoría pensada como un mero eslabón más en la cadena- no justifica la restricción del acceso a un bien que sería inconcebible sin todos los desarrollos que le han precedido, sin el general intellect de una sociedad dada. Del mismo modo que el trabajo vivo empuja los límites de lo posible introduciendo un clinamen en la repetición, toda historia contiene hilos no desarrollados, potencias cuya actualización no ha de ser impedida por el dispositivo de la propiedad. Los personajes secundarios portan historias latentes que - $y$ esta es una consideración normativa fuerte que subyace a toda la postura estético-política wumingiana - las restricciones de acceso a la obra no deben amputar. Así, el narrador que vive de su trabajo, al que los autores asignan un catálogo de derechos y deberes (Wu Ming, 2002: 33-35) en tanto que trabajador que cumple una función social, no lo hace por contar sus historias, sino por narrar historias que son también suyas a través de representaciones u objetos particulares que, estos sí, se venden como cualquier mercancía.

Estas son las coordenadas desde las que, la "empresa mental" Wu Ming, asumiendo el "dentro y contra" operaista, hace de su trabajo un intento de reorganización inmanente que, a partir de las potencias liberadas en el interior del modo de producción posfordista, aspira a prefigurar las vías de su supresión y a incentivar las fuerzas destinadas a llevarla a cabo. Aspiran con esto, en fin, a construir los imaginarios que, en el éxodo por el ignoto desierto del capital, sean las huellas en la arena que arriben al oasis de la desutopía, es decir, que sean "propuesta(s) de construcción nueva de una relación social multitudinaria que se regule conforme a la cooperación y a la autonomía" (Negri, 2016b).

\section{BIBLIOGRAFÍA}

BARTHES, Roland. (2000). Mitologías. Madrid: s. XXI.

BOLOGNA, Sergio. (2006). Crisis de la clase media y Posfordismo. Madrid: Akal.

DELEUZE, Gilles. (2005). La isla desierta y otros textos. Valencia: Pre-Textos.

FERNÁNDEZ-SAVATER, Amador. (2002). "Wu Ming, las historias como hachas de guerra" en WU MING. Esta revolución no tiene rostro. Madrid: Acuarela. 
FERNÁNDEZ-SAVATER, Amador y WU MING. (2003). "Entrevista con Wu Ming 4: Mitopoiesis y acción política" en El viejo topo, no 180, Madrid, pp. 52-63.

HEIDEGGER, Martin. (2009). Ser y tiempo. Madrid: Trotta.

LUTHER BLISSET. (2000). Pánico en las redes. Madrid: Literatura gris.

NEGRI, Antonio. (2008). La fábrica de porcelana. Madrid: Paidós.

— (2016a). Arte y multitudo, Madrid: Trotta.

- (2016b). "Con el 15M se ha producido en España una ruptura antifascista", consultado 20 de octubre de 2017, Diagonal, en https://www.diagonalperiodico.net/blogs/funda/entrevista- antonio-negri-con-15mse-ha-producido-espana-ruptura-antifascista.html .

NEGRI, Antonio y HARDT, Michael. (2003), El trabajo de Dionisos, Madrid: Akal.

RENDUELES, César. (2013). Sociofobia, Madrid: Capitán Swing.

VIRNO, Paolo. (2011). Ambivalencia de la multitud, Buenos Aires: Tinta limón.

— (2016). Gramática de la multitud. Madrid: Traficantes de sueños.

WU MING. (2002). Esta revolución no tiene rostro, Madrid: Acuarela. 